\title{
Closing the False Divide: Sustainable Approaches to Integrating Mental Health Services into Primary Care
}

\author{
Kurt Kroenke, $M D^{1,2,3}$ and Jurgen Unutzer, $M D^{4}$ \\ 'VA HSR\&D Center for Health information and Communication, Indianapolis, IN, USA; ${ }^{2}$ Department of Medicine, Indiana University School of \\ Medicine, Indianapolis, IN, USA; ${ }^{3}$ Regenstrief Institute, Inc, Indianapolis, IN, USA; ${ }^{2}$ Department of Psychiatry and Behavioral Sciences, University of \\ Washington, Seattle, WA, USA.
}

\begin{abstract}
Mental disorders account for 25\% of all health-related disability worldwide. More patients receive treatment for mental disorders in the primary care sector than in the mental health specialty setting. However, brief visits, inadequate reimbursement, deficits in primary care provider (PCP) training, and competing demands often limit the capacity of the PCP to produce optimal outcomes in patients with common mental disorders. More than 80 randomized trials have shown the benefits of collaborative care (CC) models for improving outcomes of patients with depression and anxiety. Six key components of CC include a population-based approach, measurementbased care, treatment to target strategy, care management, supervision by a mental health professional (MHP), and brief psychological therapies. Multiple trials have also shown that $\mathrm{CC}$ for depression is equally or more cost-effective than many of the current treatments for medical disorders. Factors that may facilitate the implementation of CC include a more favorable alignment of medical and mental health services in accountable care organizations and patient-centered medical homes; greater use of telecare as well as automated outcome monitoring; identification of patients who might benefit most from CC; and systematic training of both PCPs and MHPs in integrated team-based care.
\end{abstract}

J Gen Intern Med 32(4):404-10

DOI: $10.1007 / \mathrm{s} 11606-016-3967-9$

(C) The Author(s) 2016. This article is published with open access at Springerlink.com

\section{PRIMARY CARE INTEGRATION RATIONALE AND BARRIERS}

Worldwide, the prevalence of major depression and anxiety disorders is $5.6 \%$ and $4.0 \%$, respectively, and mental disorders account for nearly $25 \%$ of all health-related disability. ${ }^{1}$ Depression and anxiety are each present in about $10 \%$ of primary care patients in the US ${ }^{2}$ and are the first and fifth most common causes of years lived with disability (YLDs) among all diseases. ${ }^{3}$ Indeed, depression and anxiety alone account for as many YLDs in the US as do chronic obstructive pulmonary

Received August 8, 2016

Revised November 21, 2016

Accepted December 6, 2016

Published online February 27, 2017 disease, diabetes, Alzheimer disease, ischemic heart disease, stroke, and chronic kidney disease combined.

Of all mental health $(\mathrm{MH})$ visits, more are to primary care providers (PCPs) than to psychiatrists, and the PCP proportion has been rapidly increasing. Of the 22 visits per 100 persons in the US population to psychiatrists and PCPs that resulted in a mental health diagnosis in $2010,60 \%$ were to a PCP (compared to $54 \%$ in 1995); of the 35 visits per 100 persons that resulted in a psychotropic medication prescription, $77 \%$ were to a PCP (compared to $67 \%$ in 1995). ${ }^{4}$ A majority of patients are treated for depression exclusively in primary care (73\%) with fewer patients treated by psychiatrists $(24 \%)$ or other mental health professionals (13\%). ${ }^{5}$ Although PCPs provide the majority of $\mathrm{MH}$ visits, these visits only make up a small proportion of their overall work: $3 \%$ and $2 \%$ of PCP encounters are coded for a primary diagnosis of depression and anxiety compared with $41 \%$ and $27 \%$ of psychiatrist visits. ${ }^{4}$

Besides prevalence, other factors mandating a principal role for PCPs include a shortage of mental health specialists and the reluctance of some patients to accept a mental health referral. Fewer than one in four adults with a diagnosable mental disorder receive care from a mental health professional in any given year. ${ }^{6}$ Many patients prefer receiving treatment from providers with whom they already have an established health care relationship. ${ }^{7}$ Barriers include: (1) insufficient training and/or interest of some PCPs in managing mental disorders; (2) the brevity of primary care visits; (3) the competing demands of preventive care and treatment of comorbid medical conditions; (4) reimbursement systems that carve out mental health care or constrain payment to PCPs for adequate treatment of mental disorders; (5) confidentiality concerns of $\mathrm{MH}$ providers or patients that impede sharing of notes; (6) disagreements among different types of MH specialists on which providers should be integrated and what roles they should play

\section{KEY COMPONENTS OF EFFECTIVE INTEGRATION}

Because most trials of integrated care have tested multicomponent treatments, the evidence supports these bundled interventions as a whole rather than their discrete components (Table 1). The key components outlined in Table 2 are distilled from more comprehensive reviews. ${ }^{7-17}$ 
Table 1 Six Key Components of Integrating Mental Health into Primary Care

\begin{tabular}{|c|c|}
\hline Component & Comment \\
\hline Population based & $\begin{array}{l}\text {-Identify and track all patients with a } \\
\text { particular disorder } \\
\text { - Difficult without registry and/or care man- } \\
\text { ager }\end{array}$ \\
\hline Measurement based & $\begin{array}{l}\text { - Screening and severity assessment } \\
\text { - Regular treatment outcome monitoring }\end{array}$ \\
\hline Treatment to target & $\begin{array}{l}\text { - Regularly monitor severity of the disorder } \\
\text { - Focus on treating to desired level of the } \\
\text { outcome rather than a specific type or dose of } \\
\text { drug or psychotherapy } \\
\text { - Consult mental health specialist and/or adjust } \\
\text { or change treatment if not improving }\end{array}$ \\
\hline Care management & $\begin{array}{l}\text { - Often nurse (or social worker, pharmacist, } \\
\text { etc.) } \\
\text { - Psychoeducation, patient registry, systematic } \\
\text { tracking of adherence and clinical response, } \\
\text { coordinating care among patient, primary care } \\
\text { provider and mental health specialist }\end{array}$ \\
\hline $\begin{array}{l}\text { Psychiatric } \\
\text { supervision }\end{array}$ & $\begin{array}{l}\text { - Regular (usually weekly) meetings with care } \\
\text { manager to review patients who are not } \\
\text { improving as expected } \\
\text { - Occasional consultative session with selected } \\
\text { patients } \\
\text { - Facilitated mental health referral for more } \\
\text { complex patients }\end{array}$ \\
\hline $\begin{array}{l}\text { Brief psychological } \\
\text { therapies }\end{array}$ & $\begin{array}{l}\text { - Delivered in-clinic or by telephone or tele- } \\
\text { video } \\
\text { - Administered by trained behavioral health } \\
\text { specialist (e.g., nurse, clinical social worker, } \\
\text { psychologist, other licensed counselor) } \\
\text { - Limited number of sessions focused on } \\
\text { simpler treatments (e.g., behavioral activation, } \\
\text { problem-solving) }\end{array}$ \\
\hline
\end{tabular}

(1) Population-based care for a particular disease means systematic efforts by a health care system to identify all of its patients with that disease, provide appropriate treatment, and track outcomes. In the current context of primary care, this is difficult to do without a disease registry and care

Table 2 Practical Strategies for Smaller Primary Care Practices

\begin{tabular}{|c|c|}
\hline No. & Strategy \\
\hline 1 & $\begin{array}{l}\text { Use self-administered measures not only for screening but also to } \\
\text { monitor and adjust therapy }\end{array}$ \\
\hline 2 & $\begin{array}{l}\text { Assess suicidality efficiently (e.g., P4 screener) to stratify referral } \\
\text { urgency and develop practice protocols for the assessment, } \\
\text { triage, and follow-up of patients at risk for suicide }\end{array}$ \\
\hline 3 & $\begin{array}{l}\text { Track key treatment metrics (symptom response, adherence, side } \\
\text { effects) in home-based fashion (e.g., secure website, telephoni- } \\
\text { cally, HIPPA-compliant texting or e-mails, etc.) }\end{array}$ \\
\hline 4 & $\begin{array}{l}\text { Acquire skills in brief therapy techniques (e.g., behavioral } \\
\text { activation; motivational interviewing; problem-solving treatment) } \\
\text { and train other practice members as appropriate (e.g., social } \\
\text { workers or nurses) in such skills }\end{array}$ \\
\hline 5 & $\begin{array}{l}\text { Direct patients to self-management resources (including web- } \\
\text { based) to complement therapy }\end{array}$ \\
\hline 6 & $\begin{array}{l}\text { Educate patients with milder symptoms or in remission how to } \\
\text { detect worsening and seek care; establish relapse prevention } \\
\text { plans for patients in remission }\end{array}$ \\
\hline 7 & $\begin{array}{l}\text { Train least costly office staff for simple tasks (screening, } \\
\text { education, monitoring depressive symptom response and } \\
\text { treatment adherence, referral) }\end{array}$ \\
\hline 8 & $\begin{array}{l}\text { Establish a list/registry of patients who have initiated treatment } \\
\text { for common mental disorders and a protocol for reviewing this } \\
\text { list on a regular basis to identify patients who need changes in } \\
\text { treatment, consultation, or a higher level of care (e.g., specialty } \\
\text { referral) }\end{array}$ \\
\hline
\end{tabular}

manager. Electronic health records can facilitate the process but not without additional programming or resources to identify patients and track adherence, follow-up, and clinical outcomes. A challenge for primary care is to determine how many medical and mental health conditions can be effectively tracked from a population-based care approach. Since the number of common conditions is substantial, prioritization of diseases and integration of registries and care management resources is essential. For example, depression is a priority because untreated depression is not only prevalent and disabling but also interferes with the care of other chronic medical conditions. ${ }^{18}$

(2) Measurement-based care for some medical conditions is based upon laboratory or physiological measurements (diabetes, hyperlipidemia, hypertension) or objective measures coupled with patient symptoms and function (e.g., cardiovascular, pulmonary, and neurological diseases). For mental disorders like depression and anxiety, patient-reported outcomes (PROs) are the predominant measure guiding therapy. The ideal clinical PRO should be brief, self-report, public domain, multi-purpose (i.e., effective for screening, severity assessment, and monitoring treatment response), easy to score and interpret, and available in multiple languages. ${ }^{19}$ The Patient Health Questionnaire family of scales (e.g., PHQ-9, GAD-7) and the Patient-Reported Outcomes Measurement Information System (PROMIS) scales are two examples of PROs that meet most or all of these pragmatic criteria and are accessible at www. phqscreeners.com and www.assessmentcenter.net.

(3) Treatment to target means regularly monitoring severity of the disorder and intensifying, changing or augmenting treatment based upon target thresholds. As an example, a 3to 5-point change on the PHQ-9 is clinically significant; $a \geq 50 \%$ decrease and a score $<10$ typically signify a treatment response and a score $<5$ a remission. Scores should not be used in isolation but integrated with the patient's global sense of improvement ("Are you better, the same, or worse?"), occupational and social functioning, and duration of symptoms. A treat-to-target approach is also not wedded to a particular therapy but instead tailors the type and dose of treatment to patient preferences, treatment availability and tolerance, comorbid medical and mental disorders, and clinical response. It is essential, however, that therapies are evidence-based and adjusted if patients are not improving as expected, which requires a practice strategy to incorporate measurement (component 2) in a systematic way to monitor treatment response. ${ }^{12}$

(4) Care management involves a clinician (most commonly a nurse but in some settings a pharmacist, social worker, medical assistant, or other health care professional) with dedicated time to follow patients with particular disorders within a practice or group of practices. Common elements include maintaining a disease registry, providing disease-based education, tracking treatment 
adherence and clinical response, and triangulating care among three relevant parties - the patient, the PCP, and a behavioral health specialist such as a clinical psychologist or psychiatric consultant. Many patient contacts can be achieved telephonically, enhancing convenience and cost-effectiveness. In small or rural practices with fewer resources, individuals without specialized mental health training can perform telephone monitoring, psychoeducation, and behavioral activation. A German trial using health care assistants found benefits comparable to those seen with $\mathrm{CC}$ trials. $^{20}$

(5) Psychiatric consultation should be an accessible and dedicated component of integrated behavioral health care. A common model is for the care manager to meet weekly with a psychiatrist to discuss new patients or those who are not adequately responding to treatment in order to develop patient-specific treatment plans. The psychiatrist will occasionally have one or several inperson or tele-video sessions with selected patients. In other cases, the psychiatrist may recommend and facilitate referral of patients who need more specialized or prolonged psychotherapy or treatment for more complex conditions such as suicidal ideation, substance use disorders, and bipolar disorder or other psychotic disorders. Telepsychiatry can increase access to patients in rural areas or other primary care settings with a shortage of mental health professionals. ${ }^{21}$

(6) Although psychotropic prescribing is the most common treatment modality in primary care, brief psychological therapies such as motivational interviewing, behavioral activation, or problem-solving treatment are an important component of effectively integrated behavioral health care. Such therapies can be administered in the primary clinic or telephonically by trained behavioral health specialists (e.g., nurse, clinical social worker, psychologist, or other licensed counselor). The therapist can be the care manager or a separate clinician. The number of sessions is typically limited (e.g., eight or fewer), with the most commonly studied treatments in a meta-analysis of 34 trials being cognitive-behavioral therapy $(n=13)$, problem-solving therapy $(n=12)$, and counseling $(n=$ 8 ). ${ }^{22} \mathrm{CBT}$ for anxiety had the strongest benefits (pooled effect size of 1.06), whereas the benefits of all three treatments for depression or mixed anxiety and depression were modest (effect sizes of 0.21 to 0.33 ).

\section{MODELS OF INTEGRATION}

As noted in a 2010 report: "Collaborative care and integrated care are the two terms most often used to describe the interface of primary care and behavioral health care...Collaborative care involves behavioral health working with primary care; integrated care involves behavioral health working within and as a part of primary care. In collaborative care, patients perceive that they are getting a separate service from a specialist, albeit one who works closely with their physician. In integrated models, behavioral health care is part of the primary care and patients perceive it as a routine part of their health care." 8

The most frequently tested and evidence-based model is collaborative care (CC), an approach developed at the University of Washington in which care managers and psychiatric consultants work with primary care physicians to support medication management, provide brief counseling, and coordinate care across clinicians. An analysis of 94 trials of $\mathrm{CC}$ for mental health disorders (the most common target being depression) has conclusively demonstrated the superiority of CC compared to usual primary care in improving mental health outcomes. ${ }^{23}$ With its most extensive testing in primary care, $\mathrm{CC}$ has also proven effective in selected groups such as pregnant women, adolescents, older adults, neurology and oncology patients, and individuals with chronic pain, diabetes, and other medical disorders. ${ }^{11,24}$

An embedded behavioral specialist model (also known as co-location) has been adopted in certain primary practices - especially VA clinics but also in some non-VA primary care settings. This is most often a psychologist who offers consultative services to PCPs and provides on-site care for selected patients, particularly those who may benefit from brief psychotherapy. While popular in some health care systems, there is limited clinical trial evidence that this approach can achieve population-level improvements without paying attention to the core principles outlined in Table $1 .{ }^{25}$ Similarly, consultation-liaison psychiatry trials in primary care where a psychiatrist sees patients once or twice for assessment and management advice but does not provide active treatment have not proven this model superior to usual care. ${ }^{26}$

\section{TYPE OF MENTAL DISORDER}

Depression has far and away the most clinical trial evidence: a 2012 Cochrane review of CC for depression and anxiety revealed that most trials (74 of 79) focused on depression. ${ }^{10}$ $\mathrm{CC}$ consistently proved superior to usual care with an average effect size of 0.34 , which was sustained up to 2 years in the subset of trials examining long-term outcomes. This is in the range of a small $(0.2)$ to moderate $(0.5)$ clinical effect. ${ }^{27}$

Anxiety and related disorders were represented by only five trials in the Cochrane review: two for panic disorder (PD); one for panic disorder and generalized anxiety disorder (GAD); one for posttraumatic stress disorder (PTSD); one for PD, GAD, PTSD, and social anxiety disorder. Effect sizes $(0.30)$ were similar to those seen for depression. A recent primary care trial for PD and GAD showed a similar effect size for of 0.30 for $\mathrm{CC}^{28}$ Additional trials of CC for PTSD have been recently published, ${ }^{29}$ and of six trials, two demonstrated superiority of $\mathrm{CC} .^{30,31}$ These two positive trials had more 
consistently administered telephone-based psychotherapy, a treatment especially important for PTSD.

Chronic pain is frequently accompanied by comorbid depression or anxiety and shares some features such as stigma, being demanding in terms of time, and benefitting from CBT, self-management, and other nonpharmacological approaches. $\mathrm{CC}$ interventions benefit both pain and psychological outcomes in primary care patients with chronic pain. ${ }^{32-35} \mathrm{Al}-$ though evidence of $\mathrm{CC}$ for treating substance use disorders (SUDs) is lacking, studies adapting medication-assisted treatment to primary care settings are ongoing. Also, referral for SUD care can be facilitated in integrated systems, which in turn may improve both SUD and depression outcomes. ${ }^{36}$

Serious mental illnesses (SMIs) such as bipolar disorder and schizophrenia typically require optimal management in the MH specialty setting, although between $10 \%$ to $38 \%$ of patients with bipolar disorder are treated exclusively in primary care settings. ${ }^{37}$ Patients with SMI who are frequently cared for in public $\mathrm{MH}$ settings die as much as 25 years earlier than individuals in the general population, largely as the result of medical causes such as cardiovascular diseases and cancer rather than suicide or accidental death. ${ }^{38}$ Thus, CC intervention where a PCP optimizes the medical care of SMI patients either in the mental health clinic or with closely coordinated visits to primary care is another model of integrated care that may be potentially beneficial. ${ }^{39}$ Although successful interventions have predominantly targeted weight loss and smoking cessation and have been delivered in the psychiatric setting, ${ }^{40}$ one CC trial of medical management in SMI patients had promising results. ${ }^{38}$

A key issue is whether CC can benefit both psychological and medical disease outcomes. A meta-analysis of 24 trials testing integrated care for depression in primary care patients with chronic medical conditions found improved depression outcomes in patients with arthritis, cancer, diabetes, heart disease, and HIV; however, few trials explicitly targeted or assessed outcomes of the medical condition. ${ }^{24}$ Several trials focused on jointly managing depression combined with another condition such as chronic pain, ${ }^{33,41}$ PTSD, ${ }^{31}$ or diabetes and coronary heart disease $^{42,43}$ have demonstrated improved outcomes for both depression and the co-managed conditions. Thus, clinical practices should determine whether a care manager is to cover multiple conditions and, if so, whether the scope of practice comprises more than one type of mental disorder or several common mental and medical disorders. ${ }^{39}$

\section{ADDED BENEFITS FOR MINORITY, UNDERSERVED, AND OTHER VULNERABLE POPULATIONS}

Integrated care improves mental health outcomes in all primary care patients but may be especially beneficial in vulnerable populations. The Partners in Care study found greater improvement from CC-type programs relative to usual care for depressed African-Americans and Latinos than for whites in primary care, while the IMPACT study found comparable benefits for minority and white depressed elderly. ${ }^{44}$ The WE Care trial found that a primary care-based intervention in lowincome minority women was superior to community mental health referral. ${ }^{45}$

The contribution of contextual (e.g., housing, employment, food insecurity, violence, interpersonal stressors) and culturally relevant factors to mental disorders in vulnerable populations is substantial. A recent trial enhancing collaborations between community agencies and the health care system improved depression outcomes in predominantly minority (46\% African-American, $41 \%$ Latino) safety-net clients. ${ }^{44}$ The BRIDGE trial showed that standard CC and patient-centered culturally adapted CC had similar benefits on depression outcomes in AfricanAmerican patients, although patient satisfaction was greater in those receiving the culturally adapted approach. ${ }^{46}$ Another trial found that six telepsychiatry sessions provided by a bilingual psychiatrist to low-income Hispanic primary care patients was superior to usual care in improving depression outcomes. ${ }^{47} \mathrm{~A}$ potential resource in underserved areas is trained community health workers who can augment primary care services by screening for mental disorders, identifying contextual and cultural factors salient to depression, linking to relevant community resources, and monitoring outcomes. ${ }^{48}$

\section{COST-EFFECTIVENESS}

Of 18 RCT-based economic evaluations of CC, all demonstrated cost-effectiveness estimates below generally accepted thresholds in the US $(\$ 15,000-\$ 80000$ per qualityadjusted life-year gained vs. usual care). ${ }^{23}$ Another review of cost analyses performed in $30 \mathrm{CC}$ studies (both RCTs and other designs) concluded that there were more "positive" than "negative" results with regard to reduced health care use, averted productivity loss, and cost-effectiveness. ${ }^{49}$ Although $\mathrm{CC}$ benefits in terms of depression outcomes occur in the first year and appear sustained through at least 2 years, there may be slightly higher costs early on. ${ }^{50}$ Actual cost savings may lag behind but can become manifest after 3-4 years. In the IMPACT study, the largest trial of collaborative care to date, health care systems realized over 6 dollars in savings for every 1 dollar spent on $\mathrm{CC}$ for depression over a 4 -year period ${ }^{51}$ $\mathrm{CC}$ must be considered a bundled intervention since metaregression of trials has not shown any component to be singularly effective or superfluous. ${ }^{14}$ Because illness severity is one factor that predicts $\mathrm{CC}$ outcomes ${ }^{14}$ future research should determine whether stepped care application of CC to more severely ill individuals may be one way of conserving resources; another way is gathering data through automated monitoring. ${ }^{34,41}$. 


\section{IMPLEMENTATION}

Except in a few integrated health care systems, implementation of CC lags far behind the substantial body of clinical trial evidence supporting its use. Model programs include the TIDES program in the VA, the DIAMOND project in Minnesota, and initiatives in Washington, Intermountain Health, and the Department of Defense. ${ }^{31,52-55}$ One major barrier to wider implementation has been payment systems that have often been segregated into separate reimbursement for medical and mental health $(\mathrm{MH})$ care. The majority of MH-dedicated resources go to only $10 \%$ of all patients with $\mathrm{MH}$ disorders; $90 \%$ of patients with $\mathrm{MH}$ disorders are seen in the medical sector, and two-thirds receive no treatment for their MH disorder. ${ }^{56}$ Moreover, $20 \%$ to $40 \%$ of the total health budget is used to provide medical services for patients with $\mathrm{MH}$ disorders. Untreated MH disorders are associated with higher medical illness complication and treatment nonresponse rates, increased health care use and costs, and premature death. In 2012, the annual additional cost of medical care for the nearly 41 million Americans with $\mathrm{MH}$ conditions was an estimated \$290 billion. ${ }^{13}$ Therefore, integrated care for MH disorders may jointly benefit medical and mental health outcomes, an important consideration when aligning services and payments in accountable care organizations (ACOs).

Another barrier to implementation is a workforce inadequately trained in providing integrated, team-based care. ${ }^{57}$ The American Psychiatric Association has a grant from CMS to train 3500 psychiatrists in CC. Surveys have indicated $\mathrm{CC}$ teamwork can be rewarding for both psychiatrists ${ }^{58}$ and primary care physicians ${ }^{59}$ and have highlighted psychiatrists' educational needs. ${ }^{60}$ The American Medical Association has recently approved CPT codes for collaborative care that will be available in 2017 or 2018. ACO and Patient Centered Medical Home (PCMH) initiatives might also facilitate dissemination of $\mathrm{CC},{ }^{61}$ particularly since the National Committee for Quality Assurance has proposed measures of depression screening and remission as key quality indicators. However, two limitations of initial ACO guidelines should be addressed for optimal CC delivery. ${ }^{62}$ First, psychiatrists are the only $\mathrm{MH}$ professional defined by CMS as participating ACO clinicians, to the exclusion of social workers, psychologists, and other health professionals who may serve as care managers and behavioral health consultants in integrated settings. Second, only one of the 65 quality measures proposed for ACOs pertain to mental health care (depression screening) while no performance incentives or standard billing codes are tied to fundamental CC components such as decision support, measurement-based care, or registry maintenance.

Ways in which CC is implemented can vary. In some cases, care managers and psychiatric consultants work for the primary care clinic or health care system. In others, they may be contracted from a community mental health center or other specialty mental health programs. Care managers may be full time (in larger practices) or work part-time and provide services to several smaller practices. Psychiatric consultants often cover and consult to more than one primary care practice. Payment for these programs also varies, from salaried payment in fully capitated systems to case rate payments in managed Medicaid programs to fee-for-service payments using newly established CMS billing codes.

Table 2 lists some practical suggestions for smaller practices lacking the resources of larger integrated health systems. Because RCTs have typically tested CC as a bundled intervention, the impact of the individual strategies outlined in Table 2 is less certain. Nonetheless, practices in which all the components of $\mathrm{CC}$ are not yet feasible might find some of these strategies useful.

\begin{abstract}
Acknowledgement: This article was supported in part by a grant from the California Health Care Foundation to the Journal of General Internal Medicine (administered through UC Davis). The views expressed herein do not necessarily reflect those of the Foundation, JGIM, or SGIM.
\end{abstract}

Corresponding Author: Kurt Kroenke, MD; Regenstrief Institute, Inc, 1101 West 10th St, Indianapolis, IN 46202, USA (e-mail: kkroenke@regenstrief.org).

\section{Compliance with ethical standards:}

Conflict of Interest: Dr. Kroenke declares no conflicts of interest. Dr. Unutzer declares royalties for Chapter on Late-Life Depression in 'Up to Date.'

Open Access This article is distributed under the terms of the Creative Commons Attribution 4.0 International License (http:// creativecommons.org/licenses/by/4.0/), which permits unrestricted use, distribution, and reproduction in any medium, provided you give appropriate credit to the original author(s) and the source, provide a link to the Creative Commons license, and indicate if changes were made.

\section{REFERENCES}

1. Vos T, Flaxman AD, Naghavi M, et al. Years lived with disability (YLDs) for 1160 sequelae of 289 diseases and injuries 1990-2010: a systematic analysis for the global burden of disease study 2010. Lancet. 2012;380(9859):2 163-2196.

2. Lowe B, Spitzer RL, Williams JB, Mussell M, Schellberg D, Kroenke K. Depression, anxiety and somatization in primary care: syndrome overlap and functional impairment. Gen Hosp Psychiatry. 2008;30(3): 191-199.

3. Collaborators UBoD. The state of US health, 1990-2010: burden of diseases, injuries, and risk factors. JAMA. 2013;310(6):591-608.

4. Olfson M, Kroenke $\mathbf{K}$, Wang $\mathbf{S}$, Blanco $\mathbf{C}$. Trends in office-based mental health care provided by psychiatrists and primary care physicians. J Clin Psychiatry. 2014;75(3):247-253.

5. Olfson M, Blanco C, Marcus SC. Treatment of adult depression in the United States. JAMA Intern Med. 2016; in press.

6. Wang PS, Lane M, Olfson M, Pincus HA, Wells KB, Kessler RC. Twelvemonth use of mental health services in the United States: results from the national comorbidity survey replication. Arch Gen Psychiatry. 2005;62(6):629-640.

7. Chung H, Rostanski N, Glassberg H, Pincus HA. Advancing integration of behavioral health into primary care: a continuum-based framework. New York: United Health Fund; 2016.

8. Collins CH, D.L.; Munger, R.; Wade, T. Evolving models of behavioral health integration in primary care. New York2010

9. Katon W, Unutzer J, Wells $\mathbf{K}$, Jones L. Collaborative depression care: history, evolution and ways to enhance dissemination and sustainability. Gen Hosp Psychiatry. 2010;32:456-464.

10. Archer J, Bower P, Gilbody S, et al. Collaborative care for depression and anxiety problems. Cochrane Database Syst Rev. 2012;10, CD006525. 
11. Huffman JC, Niazi SK, Rundell JR, Sharpe M, Katon WJ. Essential articles on collaborative care models for the treatment of psychiatric disorders in medical settings: a publication by the Academy of Psychosomatic Medicine research and evidence-based practice committee. Psychosomatics. 2014;55(2):109-122.

12. Vanderlip ER, Rundell J, Avery M, et al. Dissemination of integrated care within adult primary care settings: the collaborative care model. Washington DC: American Psychiatric Association and Academy of Psychosomatic Medicine; 2016.

13. Manderscheid R, Kathol R. Fostering sustainable, integrated medical and behavioral health services in medical settings. Ann Intern Med. 2014;160(1):61-65.

14. Miller CJ, Grogan-Kaylor A, Perron BE, Kilbourne AM, Woltmann E, Bauer MS. Collaborative chronic care models for mental health conditions: cumulative meta-analysis and metaregression to guide future research and implementation. Med Care. 2013;51(10):922-930.

15. Thota AB, Sipe TA, Byard GJ, et al. Collaborative care to improve the management of depressive disorders: a community guide systematic review and meta-analysis. Am J Prev Med. 2012;42(5):525-538.

16. Woltmann E, Grogan-Kaylor A, Perron B, Georges H, Kilbourne AM, Bauer MS. Comparative effectiveness of collaborative chronic care models for mental health conditions across primary, specialty, and behavioral health care settings: systematic review and meta-analysis. Am J Psychiatry. 2012;169(8):790-804.

17. Ratzliff A, Unutzer J, Katon W, Stephens KA. Integrated Care: Creating Effective Mental and Primary Health Care Teams. Wiley; 2016.

18. Katon WJ. Clinical and health services relationships between major depression, depressive symptoms, and general medical illness. Biol Psychiatry. 2003;54(3):216-226.

19. Kroenke K, Monahan PO, Kean J. Pragmatic characteristics of patientreported outcome measures are important for use in clinical practice. J Clin Epidemiol. 2015;68(9):1085-1092.

20. Gensichen $\mathbf{J}$, von Korff $\mathbf{M}$, Peitz $\mathbf{M}$, et al. Case management for depression by health care assistants in small primary care practices: a cluster randomized trial. Ann Intern Med. 2009;151(6):369-378.

21. Fortney JC, Pyne JM, Turner EE, et al. Telepsychiatry integration of mental health services into rural primary care settings. Int. Rev. Psychiatry (Abingdon, England). 2015;27(6):525-539.

22. Cape J, Whittington C, Buszewicz M, Wallace $\mathbf{P}$, Underwood L. Brief psychological therapies for anxiety and depression in primary care: metaanalysis and meta-regression. BMC Med. 2010;8:38.

23. Reed SJ, Shore KK, Tice JA. Effectiveness and value of integrating behavioral health into primary care. JAMA Intern Med. 2016;176(5):691692.

24. Watson LC, Amick HR, Gaynes BN, et al. Practice-based interventions addressing concomitant depression and chronic medical conditions in the primary care setting: a systematic review and meta-analysis. J Prim Care Commun Health. 2013;4(4):294-306.

25. Harkness EF, Bower PJ. On-site mental health workers delivering psychological therapy and psychosocial interventions to patients in primary care: effects on the professional practice of primary care providers. Cochrane Database Syst Rev. 2009;1, CD000532.

26. Cape $\mathbf{J}$, Whittington $\mathbf{C}$, Bower $\mathbf{P}$. What is the role of consultation-liaison psychiatry in the management of depression in primary care? A systematic review and meta-analysis. Gen Hosp Psychiatry. 2010;32(3):246-254.

27. Kazis LE, Anderson JJ, Meenan RF. Effect sizes for interpreting changes in health status. Med Care. 1989;27:S178-S189.

28. Rollman BL, Belnap BH, Mazumdar S, et al. Telephone-delivered stepped collaborative care for treating anxiety in primary care: a randomized controlled trial. J Gen Intern Med. 2016; in press.

29. Schnurr PP. Extending collaborative care for posttraumatic mental health. JAMA Intern Med. 2016;176(7):956-957.

30. Fortney JC, Pyne JM, Kimbrell TA, et al. Telemedicine-based collaborative care for posttraumatic stress disorder: a randomized clinical trial. JAMA Psychiat. 2015;72(1):58-67.

31. Engel CC, Jaycox LH, Freed MC, et al. Centrally assisted collaborative telecare for posttraumatic stress disorder and depression among military personnel attending primary care: a randomized clinical trial. JAMA Intern Med. 2016;176(7):948-956.

32. Dobscha SK, Corson K, Perrin NA, et al. Collaborative care for chronic pain in primary care: a clustered randomized trial. JAMA. 2009;301(12):1242-1252.

33. Kroenke K, Bair MJ, Damush TM, et al. Optimized antidepressant therapy and pain self-management in primary care patients with depression and musculoskeletal pain: a randomized controlled trial. JAMA. 2009;301(20):2099-2110.

34. Kroenke K, Krebs EE, Wu J, Yu Z, Chumbler NR, Bair MJ. Telecare collaborative management of chronic pain in primary care: a randomized clinical trial. JAMA. 2014;312(3):240-248.

35. Bair MJ, Ang D, Wu J, et al. Evaluation of stepped care for chronic pain (ESCAPE) in veterans of the Iraq and Afghanistan conflicts: a randomized clinical trial. JAMA Intern Med. 2015;175(5):682-689.

36. Chan YF, Huang $\mathbf{H}$, Bradley $\mathbf{K}$, Unutzer J. Referral for substance abuse treatment and depression improvement among patients with cooccurring disorders seeking behavioral health services in primary care. J. Subst. Abus. Treat. 2014;46(2):106-112.

37. Kilbourne AM, Goodrich DE, O'Donnell AN, Miller CJ. Integrating bipolar disorder management in primary care. Curr. Psychiatry Rep. 2012;14(6):687-695.

38. Druss BG, von Esenwein SA, Compton MT, Rask KJ, Zhao L, Parker RM. A randomized trial of medical care management for community mental health settings: the primary care access, referral, and evaluation (PCARE) study. Am J Psychiatry. 2010;167(2):151-159.

39. Carey TS, Crotty KA, Morrissey JP, et al. Future research needs for evaluating the integration of mental health and substance abuse treatment with primary care. J Psychiatr Pract. 2013;19(5):345-359.

40. McGinty EE, Baller J, Azrin ST, Juliano-Bult D, Daumit GL. Interventions to address medical conditions and health-risk behaviors among persons with serious mental illness: a comprehensive review. Schizophr Bull. 2016;42(1):96-124.

41. Kroenke $\mathbf{K}$, Theobald $\mathbf{D}, \mathbf{W u} \mathbf{J}$, et al. Effect of telecare management on pain and depression in patients with cancer: a randomized trial. JAMA. 2010;304(2):163-171.

42. Katon WJ, Lin EH, Von Korff M, et al. Collaborative care for patients with depression and chronic illnesses. N Engl J Med. 2010;363(27):2611-2620.

43. Rossom RC, Solberg LI, Magnan S, et al. Impact of a national collaborative care initiative for patients with depression and diabetes or cardiovascular disease. Gen Hosp Psychiatry. 2016.

44. Wells KB, Jones L, Chung B, et al. Community-partnered clusterrandomized comparative effectiveness trial of community engagement and planning or resources for services to address depression disparities. J Gen Intern Med. 2013;28(10):1268-1278.

45. Miranda J, Green BL, Krupnick JL, et al. One-year outcomes of a randomized clinical trial treating depression in low-income minority women. J Consult Clin Psychol. 2006;74(1):99-111.

46. Cooper LA, Ghods Dinoso BK, Ford DE, et al. Comparative effectiveness of standard versus patient-centered collaborative care interventions for depression among African Americans in primary care settings: the BRIDGE Study. Health Serv Res. 2013;48(1):150-174.

47. Moreno FA, Chong J, Dumbauld J, Humke M, Byreddy S. Use of standard webcam and internet equipment for telepsychiatry treatment of depression among underserved Hispanics. Psychiatr Serv. 2012;63(12):1213-1217.

48. Waitzkin H, Getrich $\mathbf{C}$, Heying $\mathbf{S}$, et al. Promotoras as mental health practitioners in primary care: a multi-method study of an intervention to address contextual sources of depression. J Community Health. 2011;36(2):316-331.

49. Jacob V, Chattopadhyay SK, Sipe TA, Thota AB, Byard GJ, Chapman DP. Economics of collaborative care for management of depressive disorders: a community guide systematic review. Am J Prev Med. 2012;42(5):539-549.

50. Hunkeler EM, Katon W, Tang $\mathbf{L}$, et al. Long term outcomes from the IMPACT randomised trial for depressed elderly patients in primary care. BMJ. 2006;332(7536):259-263.

51. Unutzer J, Katon WJ, Fan MY, et al. Long-term cost effects of collaborative care for late-life depression. Am J Manag Care. 2008;14(2):95-100.

52. Luck J, Hagigi F, Parker LE, Yano EM, Rubenstein LV, Kirchner JE. A social marketing approach to implementing evidence-based practice in VHA QUERI: the TIDES depression collaborative care model. Implement Sci. 2009;4:64.

53. Solberg LI, Glasgow RE, Unutzer J, et al. Partnership research: a practical trial design for evaluation of a natural experiment to improve depression care. Med Care. 2010;48(7):576-582.

54. Unutzer J, Chan YF, Hafer E, et al. Quality improvement with pay-forperformance incentives in integrated behavioral health care. Am J Public Health. 2012;102(6):e41-45.

55. Reiss-Brennan B, Briot PC, Savitz LA, Cannon W, Staheli R. Cost and quality impact of Intermountain's mental health integration program. J Healthe Manag. 2010;55(2):97-113. discussion 113-114. 
56. Kathol RG, Kunkel EJ, Weiner JS, et al. Psychiatrists for medically complex patients: bringing value at the physical health and mental health/substance-use disorder interface. Psychosomatics. 2009;50(2):93-107.

57. Kathol RG, Butler M, McAlpine DD, Kane RL. Barriers to physical and mental condition integrated service delivery. Psychosom Med. 2010;72(6):511-518.

58. Norfleet KR, Ratzliff AD, Chan YF, Raney LE, Unutzer J. The role of the integrated care psychiatrist in community settings: a survey of psychiatrists' perspectives. Psychiatr Serv. 2016;67(3):346-349.

59. Bentham WD, Ratzliff A, Harrison D, Chan YF, Vannoy S, Unutzer J. The experience of primary care providers with an integrated mental health care program in safety-net clinics. Fam. Community Health. 2015;38(2): 158-168.

60. Ratzliff A, Norfleet $\mathbf{K}$, Chan YF, Raney L, Unutzer J. Perceived educational needs of the integrated care psychiatric consultant. Acad Psychiatry. 2015;39(4):448-456.

61. Druss BG, Mauer BJ. Health care reform and care at the behavioral health-primary care interface. Psychiatr Serv. 2010;61(11):10871092.

62. Goodrich DE, Kilbourne AM, Nord KM, Bauer MS. Mental health collaborative care and its role in primary care settings. Curr. Psychiatry Rep. 2013;15(8):383. 